\title{
PD-L1 immunostaining: what pathologists need to know
}

\author{
Mohammed Akhtar, Sameera Rashid ${ }^{*}$ (D) and Issam A. Al-Bozom
}

\begin{abstract}
Background: Immune checkpoint proteins, especially PD-L1 and PD-1, play a crucial role in controlling the intensity and duration of the immune response, thus preventing the development of autoimmunity. These proteins play a vital role in enabling cancer cells to escape immunity, proliferate and progress.

Methods: This brief review highlights essential points related to testing for immune checkpoint therapy that histopathologists need to know.

Results: In recent years, several inhibitors of these proteins have been used to reactivate the immune system to fight cancer. Selection of patients for such therapy requires demonstration of PD-L1 activation on the tumor cells, best done by immunohistochemical staining of the tumor and immune cells using various antibodies with predetermined thresholds.
\end{abstract}

Conclusions: Immune checkpoint therapy appears to be promising and is rapidly expanding to include a large variety of cancers.

Keywords: Cancer, Immune cells, PD-L1, PD-1, Immune checkpoint, T-cells, Inhibitors, Immunohistochemistry, Activation, Inhibition

\section{Introduction}

Tumor cells have surface antigens like those present on normal cells. However, they also manifest additional antigens that are either absent or expressed in minimal quantities on non-neoplastic cells. These are called tumor-specific or tumor-associated antigens (Fig. 1). Tumor antigens are present as peptides of approximately 8-10 amino acids along with major histocompatibility complex (MHC) class I and 2. Dendritic cells within tumor or in the regional lymph nodes capture these peptides and present them to the cytotoxic CD8+ T-cells resulting in proliferation and activation of these cells (Fig. 2). Activated cytotoxic T cells (ATC) return from general circulation and infiltrate the tumor microenvironment. These target and destroy tumor cells with the corresponding tumor antigen $[1,2]$.

* Correspondence: srashid2@hamad.qa

Department of Laboratory Medicine and Pathology, Hamad Medical

Corporation, P.O. Box 3050, Doha, Qatar

\section{Immune checkpoint regulators}

Under normal conditions, the immune system functions to protect the host against infectious diseases and tumors. In addition, it plays a vital role in clearing the body of unhealthy and ailing cells. An overactive immune system, however, may cause autoimmunity resulting in variable tissue damage. Immune checkpoints are inhibitory regulators of immune system that are crucial for maintaining self-tolerance and preventing autoimmunity by controlling the duration, extent, and intensity of immune response to minimize collateral tissue damage. One such checkpoint is cytotoxic T-lymphocyte-associated protein 4(CTLA4). It is constitutively expressed in regulatory $\mathrm{T}$ cells (Tregs) and is upregulated in activated conventional $\mathrm{T}$ cells. CTLA4 bears similarity to T-cell costimulatory protein CD28, and both molecules compete to bind to CD80 (B7). CTLA4, when activated by CD80, transmits an inhibitory signal to $\mathrm{T}$ cells, whereas $\mathrm{CD} 28$ transmits a stimulatory signal (Figs. 2 and 3). Another pair of cell surface proteins,

(c) The Author(s). 2021, corrected publication 2022. Open Access This article is licensed under a Creative Commons Attribution 4.0 International License, which permits use, sharing, adaptation, distribution and reproduction in any medium or format, as long as you give appropriate credit to the original author(s) and the source, provide a link to the Creative Commons licence, and indicate if changes were made. The images or other third party material in this article are included in the article's Creative Commons licence, unless indicated otherwise in a credit line to the material. If material is not included in the article's Creative Commons licence and your intended use is not permitted by statutory regulation or exceeds the permitted use, you will need to obtain permission directly from the copyright holder. To view a copy of this licence, visit http://creativecommons.org/ licenses/by/4.0/. The Creative Commons Public Domain Dedication waiver (http://creativecommons.org/publicdomain/zero/1. 0/) applies to the data made available in this article, unless otherwise stated in a credit line to the data. 


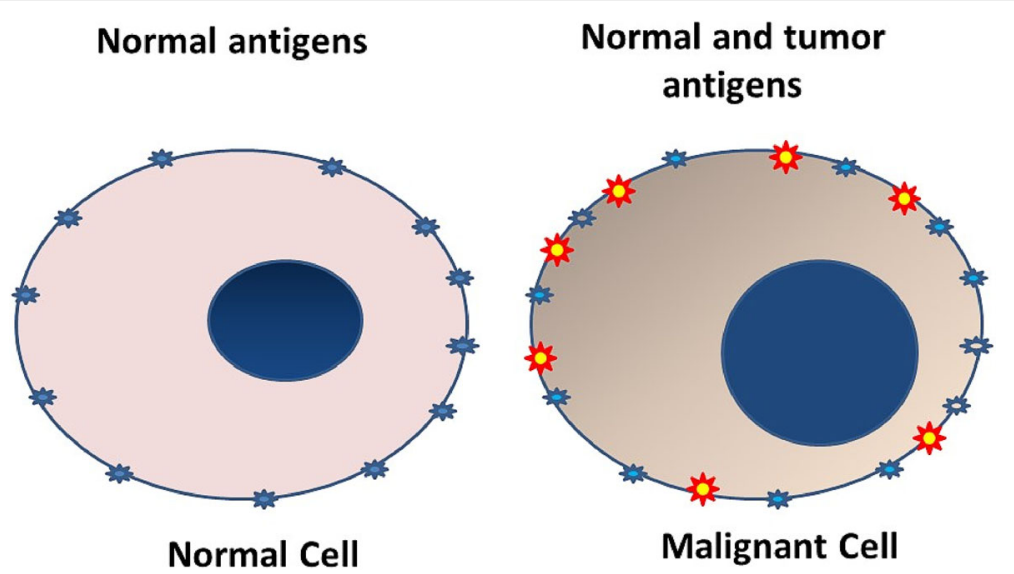

Fig. 1 Cartoon showing surface antigens on a normal cell, compared with a cancer cell which has the normal antigens as well as additional cancer-specific and cancer-related antigen (shown as yellow-red)

namely programmed cell death 1 (PD-1)/programmed cell death ligand 1 (PD-L1), plays an essential role in normal immune checkpoint function $[3,4]$.

\section{PD-1 and PDL-1}

PD-1 (CD279) is a 288-amino acid type I transmembrane protein predominantly expressed on antigenexperienced memory $\mathrm{T}$ cells in peripheral tissues and less commonly on B cells, activated monocytes, dendritic cells (DC), and natural killer (NK) cells. PD-1 is homologous to the B7 family of protein receptors and is composed of immunoglobulin V (IgV)-like extracellular domain and an intracellular domain that contains two phosphorylation sites (Fig. 4).

PD-L1 (B7-H1 or CD274) is a 290- amino acid protein, member of the B7 family of type I transmembrane protein receptors, including two extracellular domains, IgVlike and IgC-like domains; a transmembrane domain; and a cytoplasmic domain (Fig. 4). This protein is expressed on many types of cells including antigenpresenting cells (APCs), T cells, B cells, monocytes, and epithelial cells. After activation in response to pro-

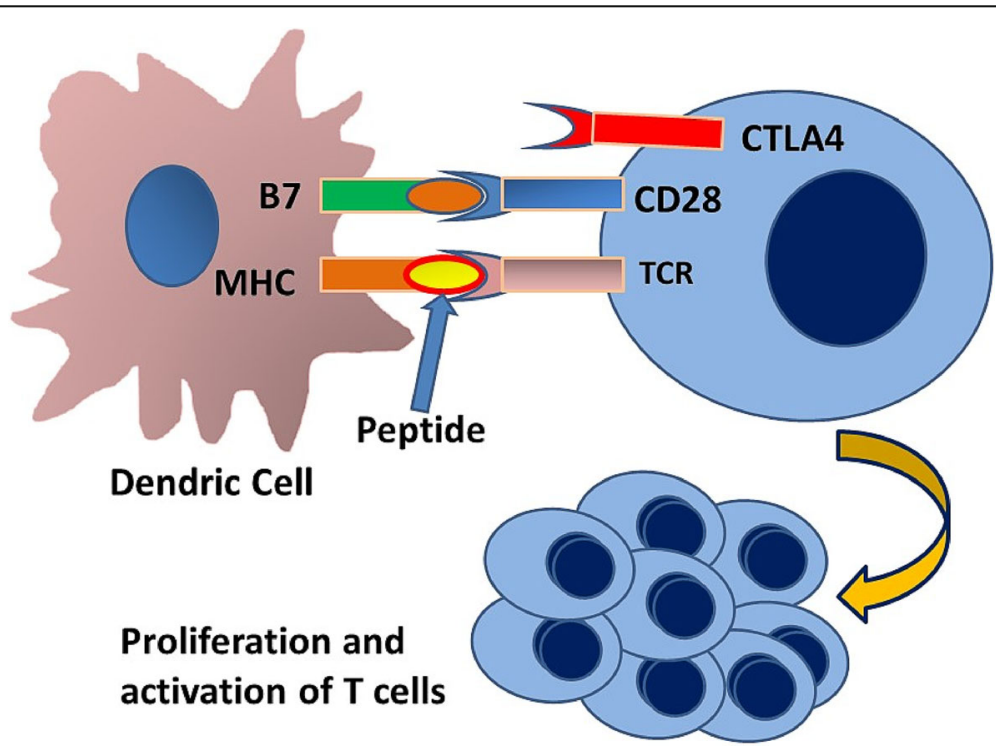

Fig. 2 Dendritic cells capture and process the cancer antigens and present these as peptides in association with MHC on the surface of the cells. The T-cell receptor on T- lymphocytes interacts with MHC and the peptide. In addition to binding to antigen-loaded MHC, T cells require a secondary signal to become activated. CD28 on the lymphocyte binds to the B7 on the surface of the dendritic cell. This interaction causes the Tcell to undergo stimulation and multiplication to become activated T-cells (ATC) 


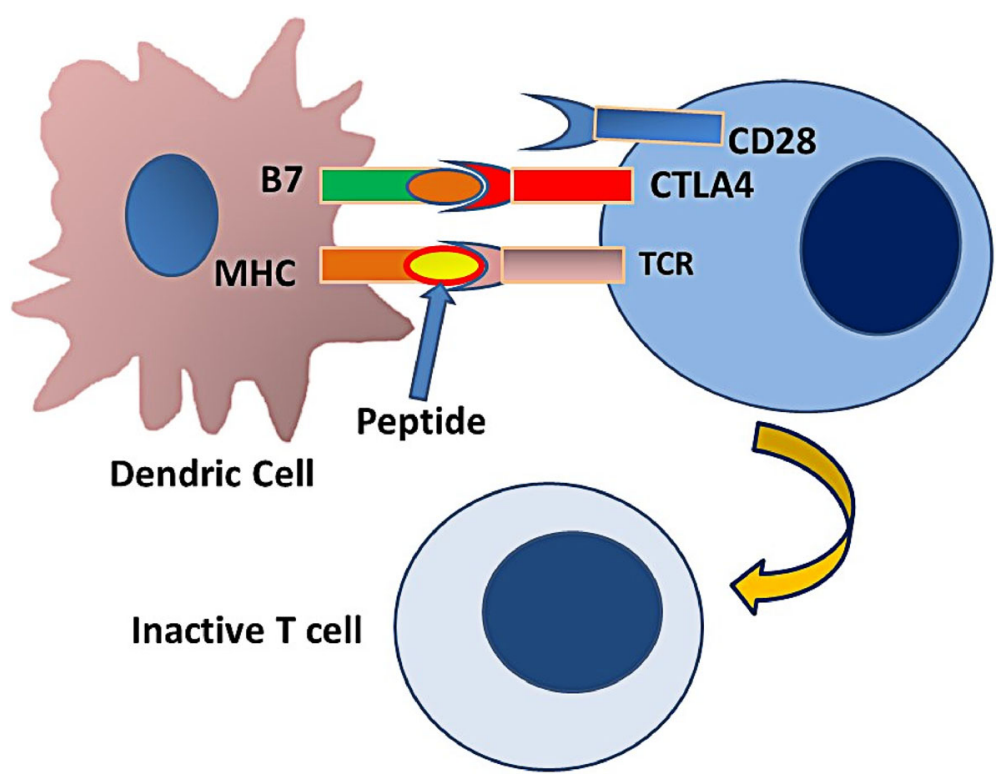

Fig. 3 CTLA4 on the surface of ATC competes with CD28 for interaction with B7. This interaction causes the T-cell to undergo regression and inactivation

inflammatory cytokines, these cells upregulate the expression of PD-1 [3-5]. In addition, the binding of PDL1 to PD-1 activates the downstream signaling of PD-1 receptor in $\mathrm{T}$ cells, thus inhibiting the proliferation, cytokine generation, release, and cytotoxicity of $\mathrm{T}$ cells (Fig. 5).

The physiological role of immune checkpoints is to prevent harmful immune attack on self-antigens during an immune response. Each checkpoint pathway decreases immune activation through intracellular signaling mechanisms and thus negatively regulates the effector immune cells by inducing $\mathrm{T}$ cell regression and exhaustion. Inhibitory checkpoint proteins, including programmed PD-1, PD-L1, or CTLA-4, can suppress antitumor T-cell responses [5, 6]. Enhancement of these checkpoint proteins is a common strategy of several solid tumors such as non-small cell lung carcinoma, malignant melanoma, or urothelial carcinoma. By upregulating PDL1 expression, these tumors use many of these pathways as crucial mechanisms to deactivate the CTLs and thereby escape antitumor immune responses.

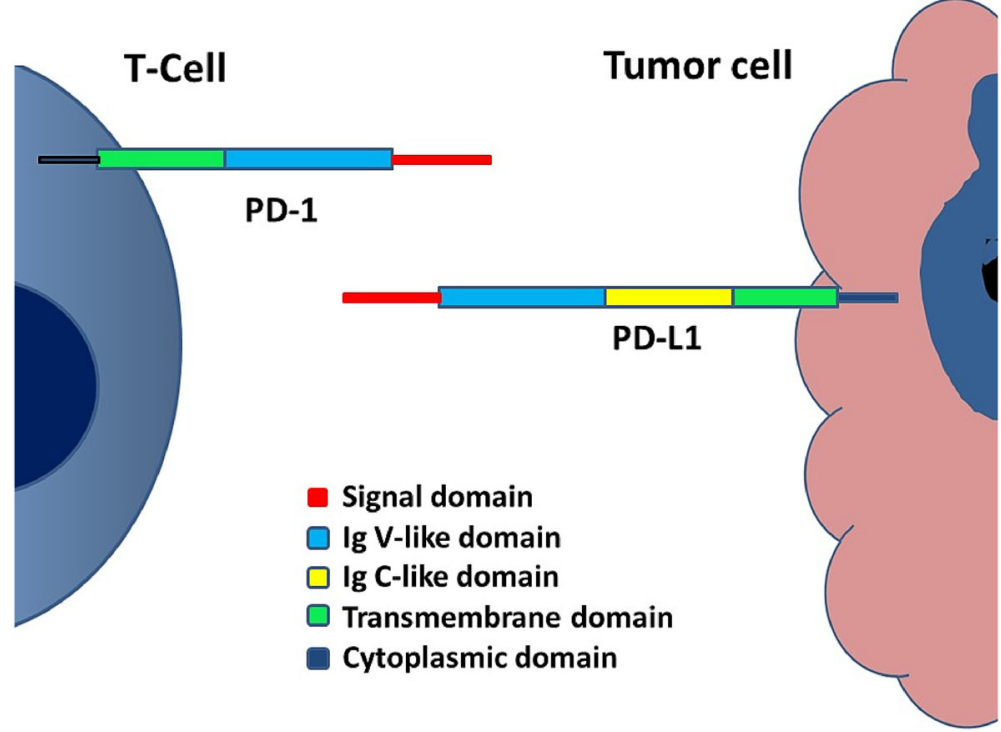

Fig. 4 Cartoon revealing the structure of PD-L1 on the tumor cell and PD-1 expressed on the surface of ATC 


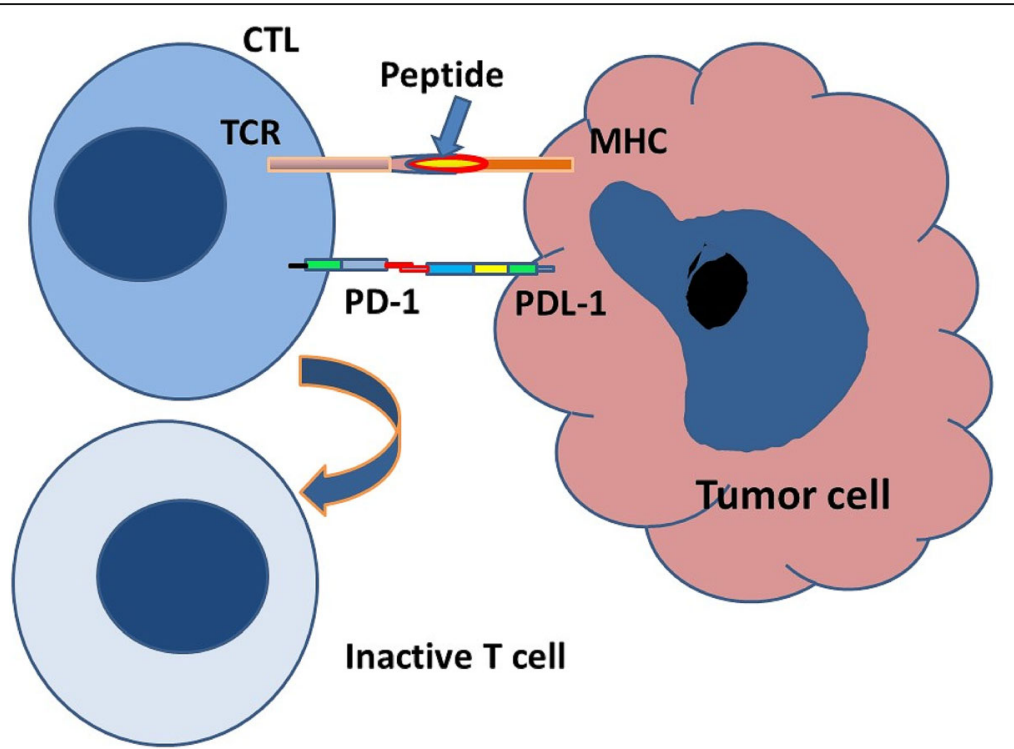

Fig. 5 Engagement of PD-L1 on the tumor cell with PD-1 on the ATC along with co-stimulation provided by T-cell receptor and MHC results in inactivation of the lymphocyte

Activated T cells infiltrate the tumor to destroy tumor cells (Fig. 6). During interaction between tumor cells and ATC, several pro-inflammatory cytokines (IFN $\gamma$, TNF- $\alpha$, IL-4, and IL-2) are released in the tumor microenvironment resulting in immunomodulation of the tumor cells, with upregulation of PD-L1expression on their surface (Fig. 7). In addition, tumor-infiltrating immune cells, including ATCs, antigen-presenting cells, and dendritic cells also upregulate the expression of PDL1 on their surface. PD-1 is constitutively present on the surface of ATCs. As PD-L1 present on the tumor cells and several immune cells engages with PD-1, it transmits a negative costimulatory signal causing ATCs to undergo inactivation, dormancy, and regression. These changes enable the tumor to bypass the immune system and ultimately progress, disseminate, and

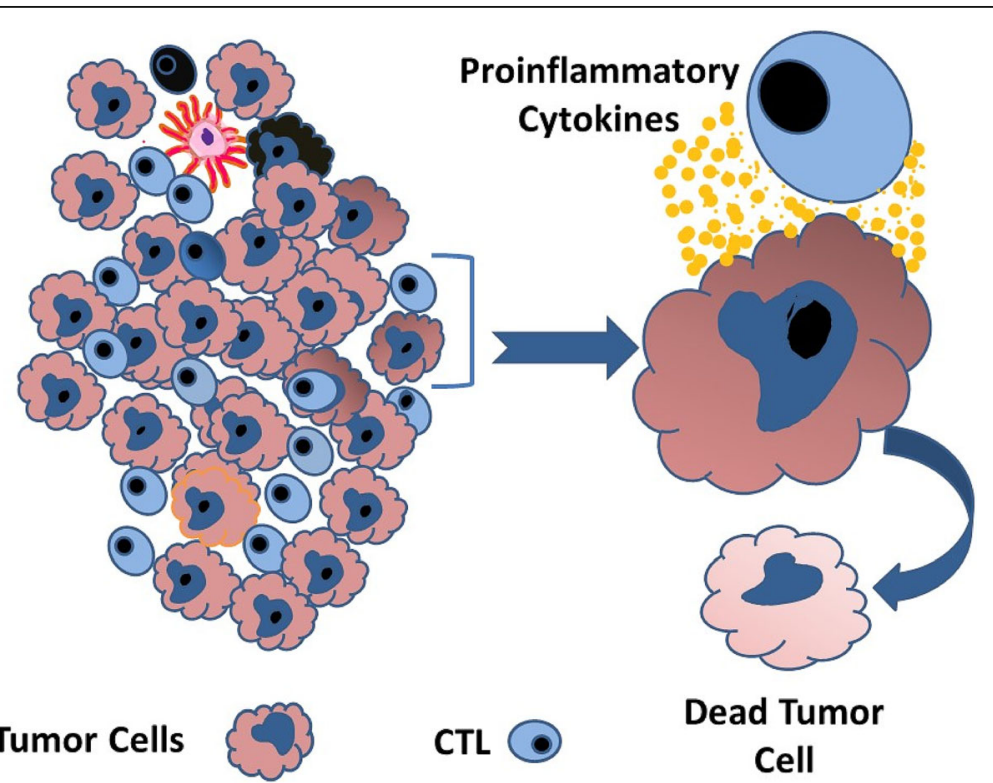

Fig. 6 Activated lymphocytes invade the tumor microenvironment and seek cancer cells for destruction. To kill the cancer cells, ATC produces pro-inflammatory cytokines, which may accumulate and alter the tumor's micro-environment. As a result, cancer cells increase the expression of PD-L1 on the cell surface 


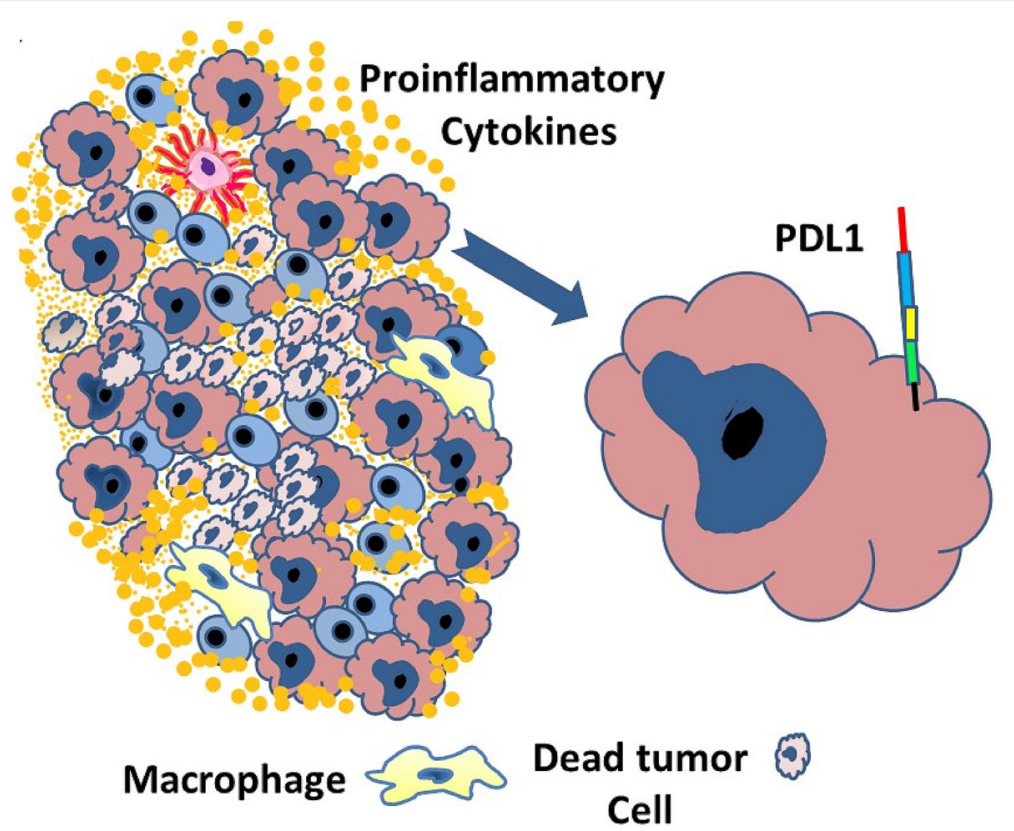

Fig. 7 Interaction of PD-L1 on cancer cells with PD-1 on the lymphocytes results in inactivation of the lymphocytes and increased numbers of Tregs, thus providing an immune inhibitory environment

metastasize. These deactivated T-cells remain inhibited but persist in the tumor microenvironment. The proinflammatory microenvironment also attracts Tregs that help maintain the $\mathrm{T}$-cell regression and dormancy (Fig. 8). These changes enable the tumor cells to bypass the immune system and undergo progression [5-9].

A tumor can become positive or negative for surface PD-L1 through several biological processes. Tumorinfiltrating $\mathrm{T}$ cells induce the tumor cells to express PDL-1; the absence of $\mathrm{T}$ cells may lead to a lack of reactive PD-L1 expression. Genetic mechanisms may also determine constitutive PD-L1 expression. There may be genetic events within the tumor cells that preclude PD$\mathrm{L} 1$ expression upon $\mathrm{T}$ cell infiltration. Thus, the presence or absence of cancer cell surface PD-L1 may have different functional meanings and treatment implications depending on the underlying mechanism of expression [10].

\section{Immune check point inhibitors}

Immunotherapy drugs called immune checkpoint inhibitors block the binding of checkpoint proteins with their partner proteins, thus preventing the inhibitory signal from being sent to the T-cells, allowing them to remain activated to kill cancer cells. The U.S. Food and Drug Administration (FDA) approved the first immune checkpoint inhibitor, ipilimumab, in 2011 to treat melanoma as an inhibitor of CTLA 4 (Bristol-Myers Squibb). In 2014 the first anti-PD-1 antibody, pembrolizumab (Merck), was approved by the FDA for use in metastatic melanoma. Since then, FDA has approved additional therapeutic monoclonal antibodies that target either PD-1 or PD-L1. These agents are available to treat various tumors, including Merkel cell carcinoma, Hodgkin lymphoma, nonsmall cell lung, renal, urinary bladder, head and neck, gastric and hepatocellular carcinoma, among others [5-9]. Some of these checkpoint inhibitors block PD1 (Pembrolizumab, Nivolumab, Cemiplimab), while others inhibit PDL1 (Atezolizumab, Avelumab, Durvalumab).

The development of immune checkpoint inhibitors has changed treatment paradigm for advanced cancers across many tumor types. Despite encouraging and sometimes remarkably durable responses in a subset of cases, most patients fail to respond. Interestingly, occasional patients in the PD-L1-negative subgroup may also benefit substantially from such therapy. Tumors have adopted the PD-1/PD-L1 axis for an immune escape to facilitate growth and progression but it may also serve as a potential therapeutic target for immune checkpoint inhibitors. These therapeutic agents, however, are very costly and may have significant side effects. Therefore, it is imperative to evaluate the tumor for increased expression of PDL1 before initiation of therapy. On this basis, PD-L1 protein expression on tumor or immune cells has emerged as the potential predictive biomarker for sensitivity to immune checkpoint blockade therapy [7-11]. 

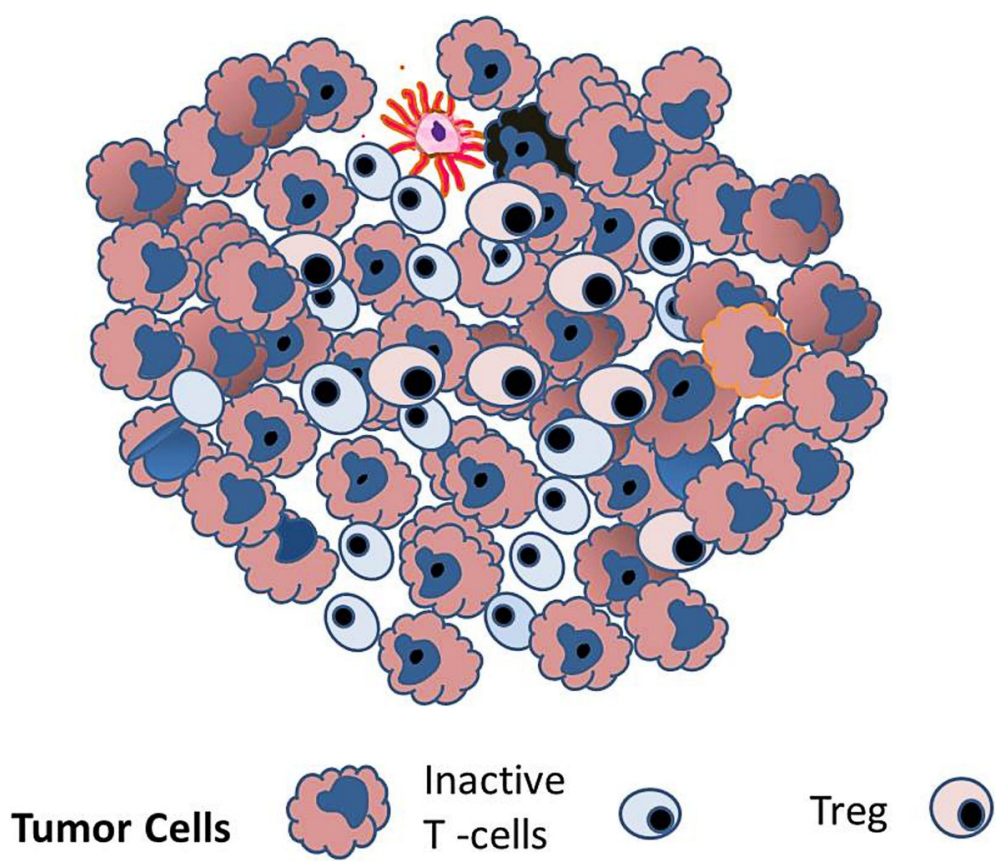

Fig. 8 As a consequence of the immune inhibitory environment, cancer cells can bypass the immune system, proliferate and undergo progression. Inactivated T-cells persist and are kept in an inactive state by Tregs

\section{Determination of PDL1 expression}

PDL1 expression may potentially be recognized and measured by a variety of available diagnostic techniques. For example, in advanced cancer, plasma PD-L1 protein levels could provide means for monitoring of PDL1 expression. Enzyme-linked immunosorbent assay (PDL1ELISA) can potentially analyze PDL1 quantitatively or qualitatively in plasma. In addition, western blot might help to detect specific proteins in tissue homogenate. Mutational findings from targeted NGS panels and study of messenger RNA and micro RNA may also provide valuable insight into the level of expression of various components of the crucial immune checkpoints in patients with cancer $[12,13]$. However, immunohistochemistry is the only widely available, practical and economical approach for studying PD-L1 expression in a tumor. Furthermore, this technique helps identify patients who may be more likely to benefit from immunotherapy with PD-1/PD-L1 inhibitors.

Many commercially available PD-L1 immunohistochemical tests are available to select patients for treatment with checkpoint inhibitors. The clinical trials that led to FDA approval of these agents used different immunohistochemical platforms with various PD-L1 antibodies to assess PDL1 expression on tumor cells, tumor-infiltrating immune cells, or both. Four PD-L1 immunohistochemical assays registered with the FDA used four different PD-L1 antibodies (22C3, 28-8, SP263, SP142) on two IHC platforms (Dako and Ventana), each with a specified scoring system. These PD-L1 antibody clones are available as prepackaged kits for use on the approved platform. The clinical trials leading to their approval used specific immune checkpoint inhibitors with specific diagnostic assays. Each of these assays uses a unique antibody with proprietary reagents, protocols, and thresholds for defining the positive expression of PD-L1 [14-16].

These trials used two types of assays: First, companion diagnostic assays, which provide required and essential information for safe and effective use of the corresponding drugs. The second group comprises complementary assays, which may be helpful but do not have a critical role in selecting patients for specific drug therapy. For example, PD-L1 IHC22C3 pharmDx tests mostly have status as companion diagnostics. On the other hand, PD-L1 IHC 28-8 pharmDx, PD-L1, Ventana PD-L1 SP142, and Ventana PD-L1 SP2632 testing are complementary diagnostics [17-19]. However, the most recently approved companion assay uses PDL1 IHC28-8 pharmDx for metastatic non-small cell lung cancer (Table 1).

Additional less expensive antibodies are available for PD-L1 staining that employ different staining platforms and protocols with varying systems of scoring and thresholds for predictive evaluation. Standardizing and validating these biomarker tests is required by using exclusively prepackaged test kits of reagents running on company-specific staining platforms. Recent studies 
Table 1 Details of FDA-approved immune checkpoint inhibitors and corresponding antibodies for immunohistochemical staining

\begin{tabular}{|c|c|c|c|c|c|c|c|}
\hline & Year & Drug & Target protein & Antibody & Threshold \% & Cell type & $\begin{array}{l}\text { Therapy } \\
\text { type }\end{array}$ \\
\hline NSCLC & 2015 & Pembrolizumab & PD-1 & $22 \mathrm{C3}$ & 50 & TC & 2nd line \\
\hline NSCLC & 2016 & Pembrolizumab & PD-1 & $22 \mathrm{C} 3$ & 1 & $\mathrm{TC}$ & 2nd line \\
\hline NSCLC & 2016 & Pembrolizumab & PD-1 & $22 C 3$ & 5 & $\mathrm{TC}$ & 1st line \\
\hline Bladder CA & 2016 & Atezolizumab & PD-L1 & SP142 & 10 & IC & 1st line \\
\hline Bladder CA & 2017 & Pembrolizumab & PD-1 & $22 \mathrm{C3}$ & 5 & IC & 1st line \\
\hline Bladder CA & 2017 & Durvalumab & PD-L1 & SP2632 & 10 & $\mathrm{IC}+\mathrm{TC}$ & 1st line \\
\hline Gastric CA & 2018 & Pembrolizumab & PD-1 & $22 \mathrm{C3}$ & 1 & $\mathrm{IC}+\mathrm{TC}$ & 3rdline \\
\hline Cervical CA & 2018 & Pembrolizumab & PD-1 & $22 \mathrm{C} 3$ & 1 & $\mathrm{IC}+\mathrm{TC}$ & 2nd line \\
\hline Triple negative Breast CA & 2019 & Atezolizumab & PD-L1 & SP142 & 1 & IC & 1st line \\
\hline NSCLC (Metastatic) & 2020 & Atezolizumab. & PD-L1 & SP142 & $\begin{array}{l}\text { TC:50 } \\
\text { IC: } 10\end{array}$ & $\mathrm{IC}+\mathrm{TC}$ & 1st line \\
\hline NSCLC (metastatic) & 2020 & Nivolumab + ipilimumab & PD-L1 & $28-8$ & 1 & TC & 1st line \\
\hline
\end{tabular}

indicate that several assays (Dako 22C3, Dako 28-8, Ventana SP263) can be used interchangeably in multiple settings except for the Ventana SP142 assay, which detected significantly fewer tumor cells than other assays [17]. Free antibody clones such as Abcam 28-8, Cell Signalling E1L3N, and others are less expensive than prepackaged counterparts. These have been suggested as possible alternatives and validated on different staining platforms without quality impairment [18]. PD-L1 tests must be reproducible, both the technical procedure of staining and the interpretation of the test by pathologists. Pre-analytical issues such as tissue fixation and processing significantly impact the outcomes of immunohistochemical reactions and might affect the result of different PD-L1 IHC tests [17-20].

\section{Interpretation and reporting}

Tumor cells that manifest membranous staining of any intensity are considered positive. Developing clinically relevant and reproducible scoring method for PD-L1 for identifying patients who will respond effectively to anti-PD-1 therapy is the key for establishment of companion or complementary diagnostic assays. The scoring method for PD-L1 IHC 22C3 PharmDx in NSCLC consists of capturing the percentage of stained tumor cells designated as tumor proportion score (TPS), which works well with nonsmall cell lung cancer (Figs. 9, 10 and 11). However, in subsequent protocols for treating gastric and other cancers, TPS was not efficient in identifying responders because it did not include tumor-infiltrating immune cells in calculating the score. Moreover, additional data indicates that PD-L1 staining on both tumor and tumor-associated immune cells has superior correlation with clinical outcome in some tumors. Therefore, a method for evaluating both cancer and immune cells in one area using the combined positive score (CPS) was developed [9, 14, 15]. CPS depends on the number of PD-L1 positive cells (including tumor cells, lymphocytes, and macrophage) in relation to total viable tumor cells, allowing quantification of tumor and immune cells in a single reading (Figs. 12, 13 and 14). A third method uses percentage of PD-L1 expression in tumor-infiltrating immune cells (IC) assessed as the proportion of tumor area occupied by PD-L1 positive immune cells of any intensity in any tissue compartment (Fig. 15). In tumor-associated

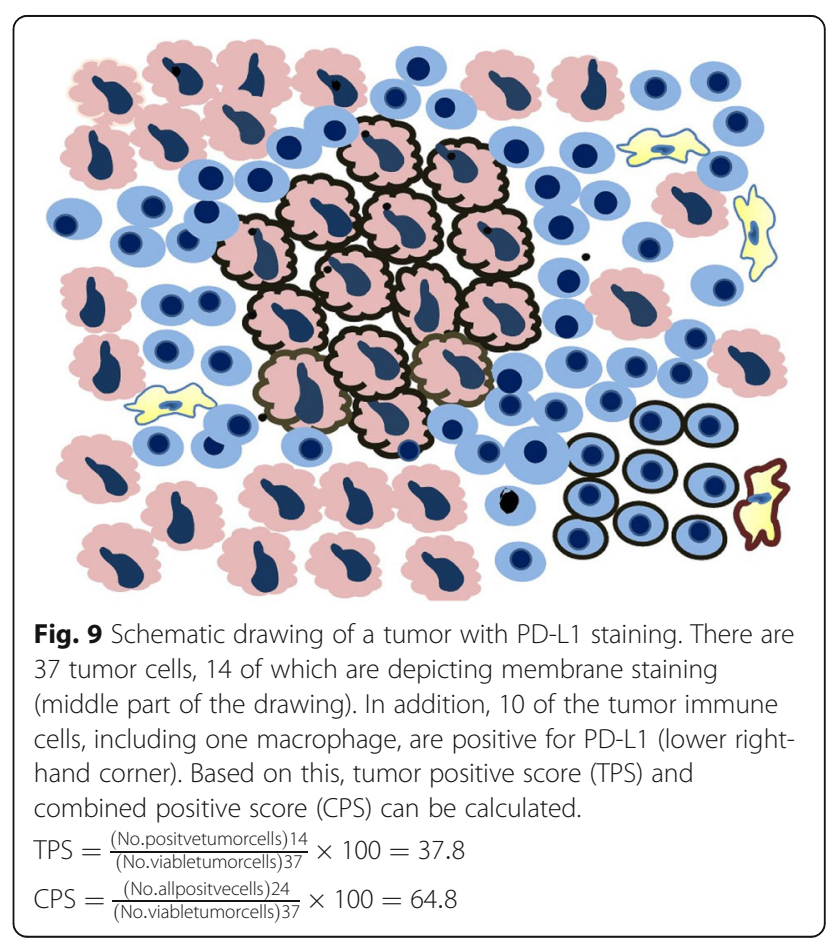



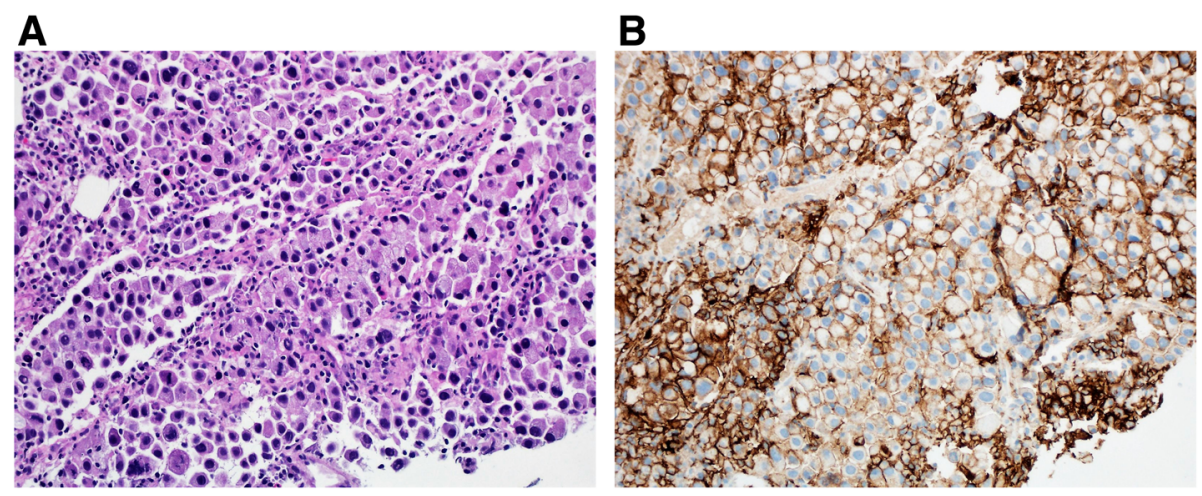

Fig. 10 A Case of pulmonary adenocarcinoma, solid type. B Immunohistochemical staining for PD-L1 showing heterogeneous staining of tumor cells ranging from 1+ to 3+ intensity. TPS: 100. (DAKO 22C3 antibody)

immune cells, membrane or cytoplasmic staining is considered positive $[19,20]$.

\section{Use of cytological material}

None of the original clinical trials for validation of PDL1 testing used cytology specimens. However, several subsequent studies using paired histology and cytology specimens were published. These studies showed that adequately cellular cytological cell blocks (more than 100 tumor cells) may be suitable for PD-L1 testing and can provide equally reliable results [21, 22]. This avenue may be advantageous when histologic material is not feasible due to the patient's condition or other circumstances. In such cases, the pathologist may establish the cancer diagnosis and provide PDL-1 test results based on cytology alone. Most published studies used cytologic material from non-small cell lung cancer obtained by endobronchial ultrasound-guided needle aspiration (EBUS-FNA) or effusion fluids. Caution is required, however, when considering the use of practices not formally validated in clinical trials to ensure that patients receive appropriate and effective treatment.

\section{Artifacts and pitfalls}

Tumor cells with complete or incomplete membrane staining are considered positive; however, in a glandforming tumor, staining limited to the luminal border is negative. In tumor-infiltrating cells, membrane, as well as cytoplasmic staining, is considered positive. Histiocytes/macrophages in various body sites may express PDL-1. Macrophages within glandular lumens may be strongly positive; however, it is regarded as a negative result if there is no staining in tumor cells. Bacteria and acellular debris may have significant positivity and should not affect stain interpretation. Intracellular pigments such as melanin, hemosiderin, and anthracosis can complicate the interpretation of staining.

Furthermore, as platelets express PD-L1, their aggregation in debris or tissue may impart false positivity. $\mathrm{Nu}$ clear staining may rarely be encountered but is not part of the scoring system. In occasional cases, tumor cells at an interface of tumor and stroma or infiltrating histiocytes/lymphocytes may appear positive but without significant staining within the more central part of the tumor. This edge effect is likely due to direct interaction
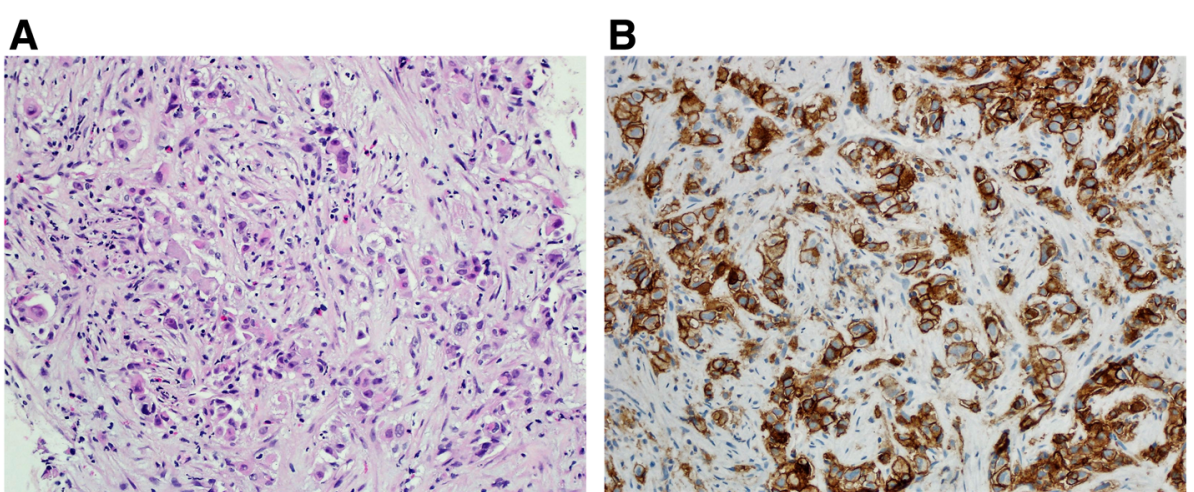

Fig. 11 A Case of metastatic pulmonary adenocarcinoma to the liver. B Immunohistochemical staining for tumor cells, moderate to intense staining (2+-3+) for PD-L1 TPS: 90 (DAKO 22C3 antibody) 

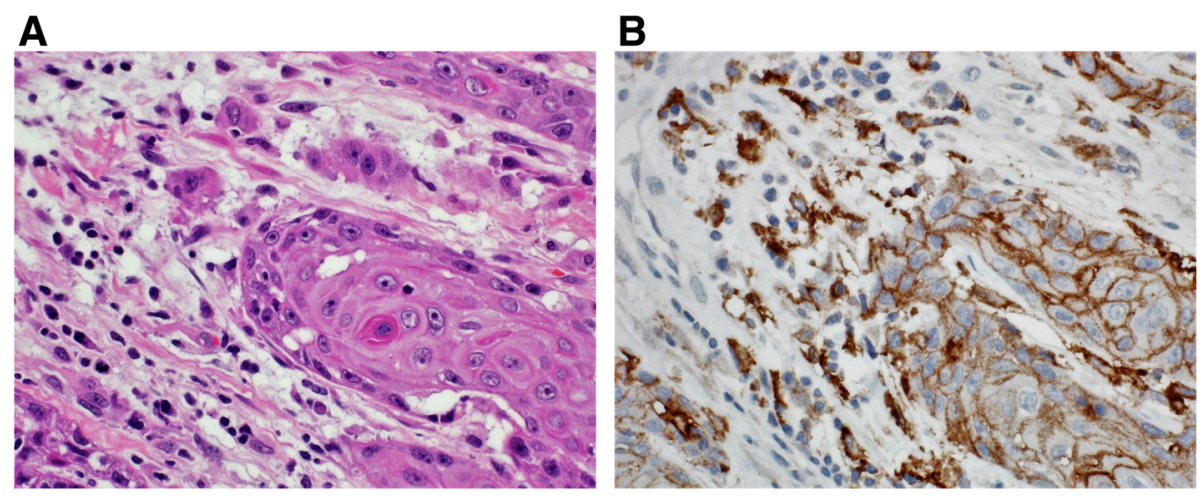

Fig. 12 A Case of buccal mucosa squamous cell carcinoma. B Immunohistochemical staining for PD-L1 revealing staining of tumor cells (right side of the figure) and tumor immune cells (left side of the figure). CPS: 90 (DAKO 22C3 antibody)

between the tumor cell antigens and upregulation of PD-L1 expression by adjacent immune cells rather than the tumor cells. In cytologic specimen, when tumor cells are sparse, interpretation and scoring can be a challenge. Some cytologic preparations may contain an excess of histiocytes and tumor cells of comparable size, and it may be difficult to distinguish the two. Regardless of the nature of the biopsy, careful assessment of immunohistochemical stains, evaluation of positive and negative controls, as well as comparison with hematoxylin and eosin-stained tissue can minimize these difficulties [23].

\section{Resistance to immune checkpoint therapy}

PD-1/PD-L1 blockade is a promising revolutionary cancer treatment strategy. Over the last decade, PD-1/PDL1 inhibitors have been tested in a number of malignancies with considerable success. In addition, it has shown sustained survival benefits in multiple tumors and is at the forefront of cancer immunotherapy. Unfortunately, just as tumor cells can avoid immune evasion, several cancers may also evolve to resist PD-1/PDL1 blockade therapy. Thus, despite the potentially cure-like survival benefit, only a minority of patients experience a prolonged and sustained curative response to PD-1/PD-L1 blockade treatment [24].

Furthermore, the lack of long-term response to therapy is usually due to an acquired resistance that might eventually lead to cancer progression in patients with initially positive clinical response. Accordingly, the resistance to PD-1/PD-L1 blockade remains a significant challenge hindering its further application. Nevertheless, substantial efforts are underway to overcome the therapy resistance and to improve clinical response with minimal immune-mediated toxicity [24].

The effect of chemotherapy on programmed cell deathligand 1 (PD-L1) expression

A few studies have investigated the variation of PD-L1 immunostaining after neoadjuvant chemotherapy and explored the association between chemotherapy response, prognosis, and the increase or decrease of PDL1 expression in cancer patients [25, 26]. Elevation of

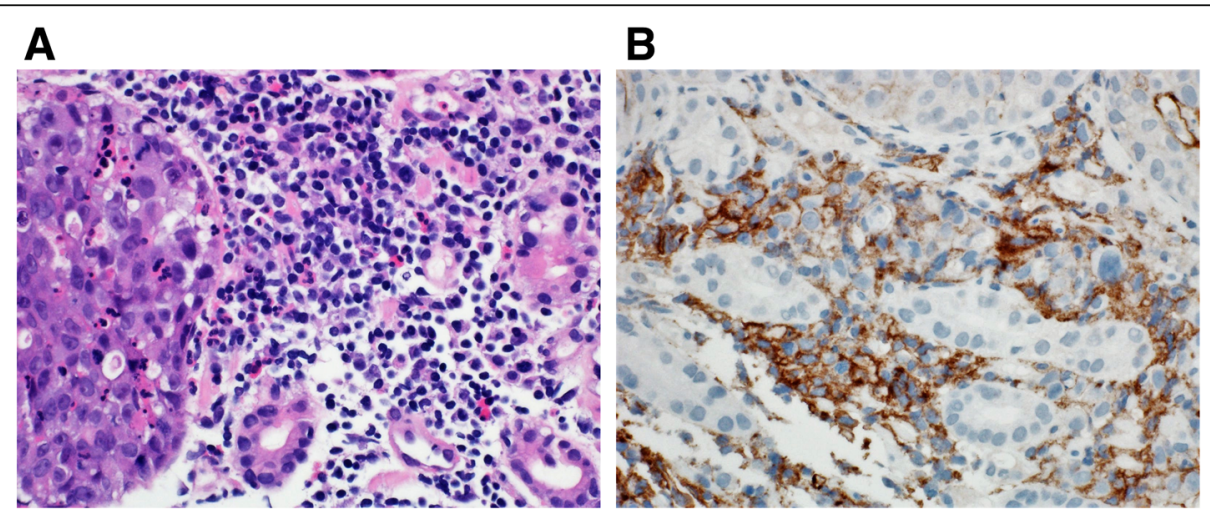

Fig. 13 A Case of poorly differentiated gastric adenocarcinoma. B Immunohistochemical staining of the tumor showing staining of tumor immune cells while tumor cells are predominantly negative. CPS: 20. (DAKO 22C3 antibody) 

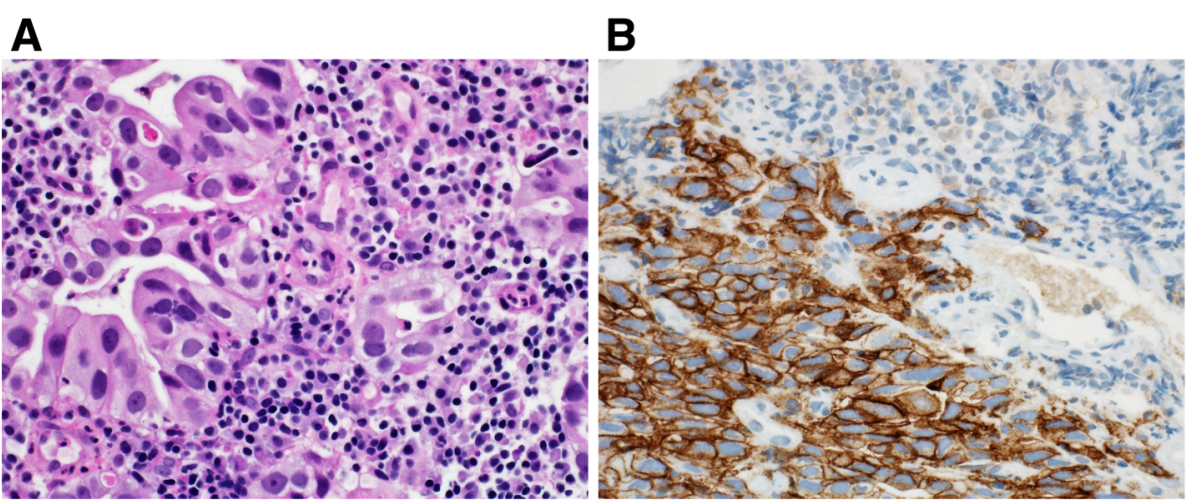

Fig. 14 A Case of moderately differentiated gastric adenocarcinoma. B immunohistochemical staining of the tumor in which only tumor cells are positive for PD-L1; while tumor immune cells are negative. CPS: 80. (DAKO 22C3 antibody)

PD-L1 expression after neoadjuvant chemotherapy may be associated with altered chemotherapy response and progression-free survival. However, additional studies are required to evaluate the significance of these findings.

\section{Automation of PDL-1 interpretation}

Manual scoring of PDL-1 IHC slides by pathologists may be a potential source of error. The increasing adoption of digital pathology and artificial intelligence in daily workflow of the laboratory provides an opportunity to leverage these tools towards improving the clinical value of PD-L1 IHC assays. Several recent studies have demonstrated that automated digital image analysis provides accuracy and consistency comparable to manual scoring. As such, image analysis scoring could serve as a crucial aid for pathologists in PD-L1 diagnostic testing [27-29].

In summary, considerable progress has been made towards understanding the role of immune checkpoint

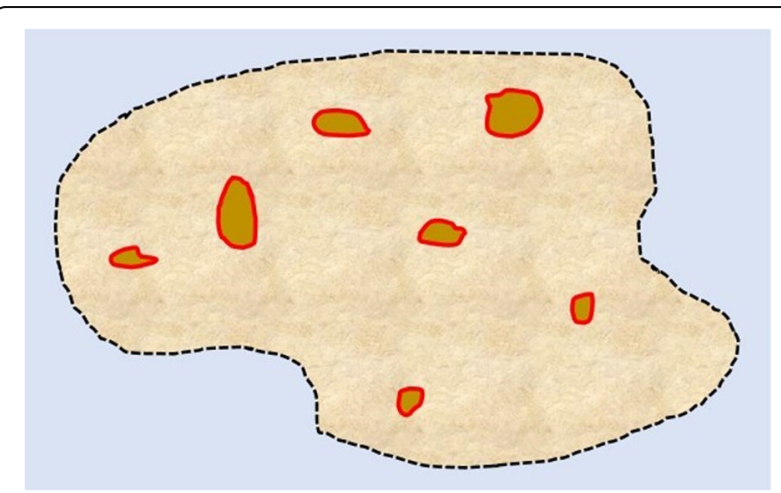

Fig. 15 A diagram depicting expression of PD-L1 positive tumor infiltrating immune cells (marked by red border) in an area of tumor cells (marked by black dotted line). The proportion of tumor area occupied by PD-L1-positive immune cells of any intensity determines the immune cell (IC) score inhibitors in treating various cancers. PD-L1 testing for the selection of patients before administering therapy is a valuable technique, and its use is constantly expanding and evolving.

\section{Abbreviations \\ ATC: Activated cytotoxic T cells; MHC: Major histocompatibility complex; CTLA4: Cytotoxic T-lymphocyte-associated protein 4; TREG: Regulatory T cells; PD-1: Programmed cell death 1; PDL-1: Programmed cell death ligand 1; DC: Dendritic cells; N.K: Natural killer; NSCLC: Non-small cell lung cancer; TPS: Tumor proportion score; CPS: Combined positive score.}

\section{Acknowledgements}

Not applicable.

\section{Authors' contributions}

Dr Akhtar developed the concept and design, Dr Issam was involved in acquisition of data, analysis and interpretation of data. Dr Sameera was involved in acquisition of data. The author(s) read and approved the final manuscript.

\section{Funding}

Not applicable.

Availability of data and materials

Not applicable.

\section{Declarations}

Ethics approval and consent to participate

Not applicable.

\section{Consent for publication}

Not applicable.

\section{Competing interests}

The authors declare that they have no competing interests.

Received: 27 January 2021 Accepted: 22 September 2021 Published online: 25 October 2021

\section{References}

1. Vigneron N. Human tumor antigens and cancer immunotherapy. Biomed Res Int. 2015;2015:948501. https://doi.org/10.1155/2015/948501 Epub 2015 Jun 16. PMID: 26161423; PMCID: PMC4487697.

2. Jiang T, Shi T, Zhang H, Hu J, Song Y, Wei J, Ren S, Zhou C. Tumor neoantigens: from basic research to clinical applications. J Hematol Oncol. 2019;12(1):93. https://doi.org/10.1186/s13045-019-0787-5. PMID: 31492199; PMCID: PMC6731555. 
3. Pardoll DM. The blockade of immune checkpoints in cancer immunotherapy. Nat Rev Cancer. 2012;12(4):252-64. https://doi.org/10.1038/ nrc3239. PMID: 22437870; PMCID: PMC4856023.

4. He X, Xu C. Immune checkpoint signaling and cancer immunotherapy. Cell Res. 2020;30(8):660-9. https://doi.org/10.1038/s41422-020-0343-4 Epub 2020 May 28. PMID: 32467592; PMCID: PMC7395714.

5. Akinleye A, Rasool Z. Immune checkpoint inhibitors of PD-L1 as cancer therapeutics. J Hematol Oncol. 2019;12(1):92. https://doi.org/10.1186/s13045019-0779-5. PMID: 31488176; PMCID: PMC6729004

6. Picardo SL, Doi J, Hansen AR. Structure and optimization of checkpoint inhibitors. Cancers (Basel). 2019;12(1):38. https://doi.org/10.3390/cancers1201 0038. PMID: 31877721 ; PMCID: PMC7017177

7. Sun L, Zhang L, Yu J, Zhang Y, Pang X, Ma C, Shen M, Ruan S, Wasan HS, Qiu S. Clinical efficacy and safety of anti-PD-1/PD-L1 inhibitors for the treatment of advanced or metastatic cancer: a systematic review and metaanalysis. Sci Rep. 2020;10(1):2083. https://doi.org/10.1038/s41598-02058674-4. PMID: 32034198; PMCID: PMC7005709.

8. Wei SC, Duffy CR, Allison JP. Fundamental mechanisms of immune checkpoint blockade therapy. Cancer Discov. 2018;8(9):1069-86. https://doi. org/10.1158/2159-8290.CD-18-0367 Epub 2018 Aug 16. PMID: 30115704.

9. Darvin P, Toor SM, Sasidharan Nair V, Elkord E. Immune checkpoint inhibitors: recent progress and potential biomarkers. Exp Mol Med. 2018; 50(12):1-11. https://doi.org/10.1038/s12276-018-0191-1. PMID: 30546008; PMCID: PMC6292890.

10. Ribas A, Hu-Lieskovan S. What does PD-L1 positive or negative mean? J Exp Med. 2016;213(13):2835-2840. https://doi.org/10.1084/jem.20161462. Epub 2016 Nov 30. PMID: 27903604; PMCID: PMC5154949.

11. Han Y, Liu D, Li L. PD-1/PD-L1 pathway: current researches in cancer. Am J Cancer Res. 2020;10(3):727-742. PMID: 32266087; PMCID: PMC7136921.

12. Arora S, Velichinskii R, Lesh RW, Ali U, Kubiak M, Bansal P, Borghaei $H_{\text {, }}$ Edelman MJ, Boumber Y. Existing and emerging biomarkers for immune checkpoint immunotherapy in solid tumors. Adv Ther. 2019;36(10):2638-78. https://doi.org/10.1007/s12325-019-01051-z Epub 2019 Aug 13. PMID: 31410780; PMCID: PMC6778545.

13. Mildner F, Sopper S, Amann A, Pircher A, Pall G, Köck S, Naismith E, Wolf D, Gamerith G. Systematic review: soluble immunological biomarkers in advanced non-small-cell lung cancer (NSCLC). Crit Rev Oncol Hematol. 2020;153:102948. https://doi.org/10.1016/j.critrevonc.2020.102948 Epub 2020 May 5. PMID: 32645684.

14. Davis AA, Patel VG. The role of PD-L1 expression as a predictive biomarker: an analysis of all U.S. Food and Drug Administration (FDA) approvals of immune checkpoint inhibitors. J Immunother Cancer. 2019;7(1):278. https:// doi.org/10.1186/s40425-019-0768-9. PMID: 31655605; PMCID: PMC6815032.

15. Ancevski Hunter $K$, Socinski MA, Villaruz LC. PD-L1 testing in guiding patient selection for PD-1/PD-L1 inhibitor therapy in lung cancer. Mol Diagn Ther. 2018;22(1):1-10. https://doi.org/10.1007/s40291-017-0308-6 PMID: 29119407; PMCID: PMC5773410.

16. Udall M, Rizzo M, Kenny J, Doherty J, Dahm S, Robbins P, Faulkner E. PD-L1 diagnostic tests: a systematic literature review of scoring algorithms and test-validation metrics. Diagn Pathol. 2018;13(1):12. https://doi.org/10.1186/ s13000-018-0689-9. PMID: 29426340; PMCID: PMC5807740.

17. Parra ER, Villalobos P, Mino B, Rodriguez-Canales J. Comparison of different antibody clones for immunohistochemistry detection of programmed cell death ligand 1 (PD-L1) on non-small cell lung carcinoma. Appl Immunohistochem Mol Morphol. 2018;26(2):83-93. https://doi.org/10.1097/ PAl.0000000000000531. PMID: 28719380; PMCID: PMC5815635.

18. de Ruiter EJ, Mulder FJ, Koomen BM, Speel EJ, van den Hout MFCM, de Roest RH, Bloemena E, Devriese LA, Willems SM. Comparison of three PD-L1 immunohistochemical assays in head and neck squamous cell carcinoma (HNSCC). Mod Pathol. 2021;34(6):1125-32. https://doi.org/10.1038/s41379-02 0-0644-7 Epub 2020 Aug 5. PMID: 32759978

19. Sun C, Mezzadra R, Schumacher TN. Regulation and function of the PD-L1 checkpoint. immunity. 2018;48(3):434-452. https://doi.org/10.1016/j.immuni.2 018.03.014. PMID: 29562194; PMCID: PMC7116507.

20. Hutarew G. PD-L1 testing, fit for routine evaluation? From a patholoï» ¿gist's point of view. Memo. 2016;9(4):201-206. https://doi.org/10.1007/s12254-0160292-2. Epub 2016 Oct 28. PMID: 28058063; PMCID: PMC5165031.

21. Lou SK, Ko HM, Kinoshita T, MacDonald S, Weiss J, Czarnecka-Kujawa K, Boerner SL, Yasufuku K, Tsao MS, Schwock J. Implementation of PD-L1 22C3 IHC pharmDxTM in cell block preparations of lung cancer: concordance with surgical resections and technical validation of CytoLyt ${ }^{\oplus}$ Prefixation.
Acta Cytol. 2020;64(6):577-87. https://doi.org/10.1159/000508628 Epub 2020 Jun 29. PMID: 32599583; PMCID: PMC7677989.

22. Zou Y, Xu L, Tang Q, You Q, Wang X, Ding W, Zhao J, Ren G. Cytology cell blocks from malignant pleural effusion are good candidates for PD-L1 detection in advanced NSCLC compared with matched histology samples. BMC Cancer. 2020;20(1):344. https://doi.org/10.1186/s12885-020-06851-z. PMID: $32321471 ;$ PMCID: PMC7178995.

23. O'Malley DP, Yang Y, Boisot S, Sudarsanam S, Wang JF, Chizhevsky V, Zhao G, Arain S, Weiss LM. Immunohistochemical detection of PD-L1 among diverse human neoplasms in a reference laboratory: observations based upon 62,896 cases. Mod Pathol. 2019;32(7):929-42. https://doi.org/10.1038/ s41379-019-0210-3 Epub 2019 Feb 13. PMID: 30760860; PMCID: PMC6760643.

24. Sun JY, Zhang D, Wu S, Xu M, Zhou X, Lu XJ, Ji J. Resistance to PD-1/PD-L1 blockade cancer immunotherapy: mechanisms, predictive factors, and future perspectives. Biomark Res. 2020;8:35. https://doi.org/10.1186/s40364020-00212-5. PMID: 32864132; PMCID: PMC7450549.

25. Guo L, Song P, Xue X, Guo C, Han L, Fang Q, Ying J, Gao S, Li W. Variation of programmed death ligand 1 expression after platinum-based neoadjuvant chemotherapy in lung cancer. J Immunother. 2019;42(6):21520. https://doi.org/10.1097/CJ.0000000000000275 PMID: 31145232; PMCID: PMC6587215.

26. Liang Y, Yu M, Zhou Caiyun, Zhu X. Variation of PD-L1 expression in locally advanced cervical cancer following neoadjuvant chemotherapy. Diagn Pathol. 2020;15(1):67. https://doi.org/10.1186/s13000-020-00977-1. PMID: 32493336; PMCID: PMC7271386.

27. Widmaier M, Wiestler T, Walker J, Barker C, Scott M, Sekhavati F, Budco A, Schneider K, Segerer F, Steele K, Rebelatto M. Comparison of continuous measures across diagnostic PD-L1 assays in non-small cell lung cancer using automated image analysis. Mod Pathol. 2020;33:380-90 PMID: 31527709 PMCID: PMC7051919.

28. Inge $\sqcup$, Dennis E. Development and applications of computer image analysis algorithms for scoring of PD-L1 immunohistochemistry. ImmunoOncol Technol. 2020;6:2-8. https://doi.org/10.1016/j.iotech.2020.04.001. PMID: 32493336 PMCID: PMC7271386.

29. Koelzer VH, Gisler A, Hanhart JC, Griss J, Wagner SN, Willi N, Cathomas G, Sachs M, Kempf W, Thommen DS, Mertz KD. Digital image analysis improves precision of PD-L1 scoring in cutaneous melanoma. Histopathology. 2018;73(3):397-406. https://doi.org/10.1111/his.13528. Epub 2018 Jun 5. PMID: 29660160

\section{Publisher's Note}

Springer Nature remains neutral with regard to jurisdictional claims in published maps and institutional affiliations.
Ready to submit your research? Choose BMC and benefit from:

- fast, convenient online submission

- thorough peer review by experienced researchers in your field

- rapid publication on acceptance

- support for research data, including large and complex data types

- gold Open Access which fosters wider collaboration and increased citations

- maximum visibility for your research: over $100 \mathrm{M}$ website views per year

At $\mathrm{BMC}$, research is always in progress.

Learn more biomedcentral.com/submissions 